\title{
IMFERON DRIP IN A UNIT
}

\author{
Major S. BERNSTEIN, ${ }^{*}$ \\ B.A., M.B., B.Ch., B.A.O., R.A.M.C.
}

IN 1963, I was posted as Regimental Medical Officer to the Training Depot Brigade of Gurkhas at Sungei Patani, Kedah, Malaysia. Part of my work was the medical care of Gurkha wives and children. There was a small Gurkha Families Hospital with 11 beds, 3 of which were for maternity cases.

One of the biggest problems in dealing with Gurkha families is the anaemia in pregnant women. During my time at the Depot Brigade of Gurkhas, I saw 170 pregnant women and the average haemoglobin at first attendance, at the ante-natal clinic was 55-60 per cent. On first attending the ante-natal clinic, iron tablets and vitamins were given as a routine, and the woman was also dewormed. At 28 weeks pregnancy each woman then received folic acid tabs I three times daily, in addition to iron and vitamins. Despite oral iron, the haemoglobin failed to rise significantly. Each woman DID take her tablets because a "pill parade" was held each morning and a record of attendance was kept, and checked weekly by myself.

As the Depot was 80 miles from the nearest British Military Hospital, this was a worrying problem, because it was impossible to keep stocks of blood for transfusion purposes in the unit. I felt it might be practical to use IMFERON by drip for the more anaemic of these women. Unfortunately at this time, Imferon had been withdrawn from the Joint Services Medical Catalogue, but I was able to acquire a small amount initially.

The usual formula for the amount of Imferon required to be given by drip is $4 / 5$ (100 minus present haemoglobin $)=$ amount in millilitres e.g., if the haemoglobin was 60 per cent then the amount of Imferon required $=32$ millilitres. Because of the short supply of Imferon, I reduced the factor $4 / 5$ to $3 / 5$.

All the blood reports on the women who received the Imferon drip showed a microcytic hypochromic anaemia. Prior to the drip being commenced, 2 millilitres Imferon were given intramuscularly, as a test dose 5 days previously.

The following Table shows the response to Imferon with comments on certain of the patients.

\section{Notes on the Various Cases}

Patient No. 1. This lady had her baby by Caesarean Section.

Patient No. 4. Had a Post Partum Haemorrhage (PPH) of 12 ozs.

Patient No. 8. Had a reaction immediately after drip was started. Reaction manifested as dyspnoea and erythema of the skin. The drip was stopped immediately, and she has since produced a healthy baby.

Patient No. 11. Reaction noted after approx. half of the drip had been completed. Reaction manifested as an urticaria. The drip was stopped immediately and intra muscular phenergan given. Patient was perfectly well in 2 hours.

Patient No. 9. I can offer no explanation as to why the haemoglobin dropped 4 per cent. This lady was a primipara, and had a hospital delivery. She received 2 pints of blood prior to delivery and also had a post partum haemorrhage.

Patient No. 13. This lady was posted to another part of Malaya.

*Now at the Medical Centre, 3rd Royal Anglian Regt., Wavell Barracks, B.F.P.O. 45. 


\begin{tabular}{|c|c|c|c|c|c|c|c|}
\hline \multirow{2}{*}{$\begin{array}{l}\text { Patient } \\
\text { No. }\end{array}$} & \multirow{2}{*}{ AGE } & \multirow{2}{*}{$\begin{array}{c}\text { Pregnancy } \\
\text { in } \\
\text { WeEkS }\end{array}$} & \multirow{2}{*}{$\begin{array}{l}\text { Amt. of } \\
\text { IMFERON } \\
\text { given } \\
\text { in ccs. }\end{array}$} & \multirow{2}{*}{$\begin{array}{l}\text { HAEMO- } \\
\text { GLOBIN } \\
\text { before } \\
\text { drip }\end{array}$} & \multicolumn{2}{|c|}{$\begin{array}{l}\text { HAEMOGLOBIN } \\
\text { after drip }\end{array}$} & \multirow{2}{*}{$\begin{array}{l}\text { AvERAGE } \\
\text { RISE on } \\
\text { FaLL }\end{array}$} \\
\hline & & & & & $\begin{array}{l}10-14 \\
\text { days }\end{array}$ & $\begin{array}{c}6 \\
\text { weeks }\end{array}$ & \\
\hline$*_{1}$ & 32 & 36 & 24 & $61 \%$ & $77 \%$ & $64 \%$ & $+16 \%$ \\
\hline 2 & 26 & 30 & 24 & $61 \%$ & $.67 \%$ & $72 \%$ & $+11 \%$ \\
\hline 3 & 29 & 30 & 28 & $45 \%$ & $57 \%$ & $54 \%$ & $+12 \%$ \\
\hline$* 4$ & 21 & 36 & 28 & $56 \%$ & $53 \%$ & $72 \%$ & $+16 \%$ \\
\hline 5 & 25 & 38 & 28 & $57 \%$ & $67 \%$ & 一 & $+10 \%$ \\
\hline 6 & 29 & 36 & 30 & $45 \%$ & $69 \%$ & $67 \%$ & $+24 \%$ \\
\hline 7 & 27 & 32 & 24 & $64 \%$ & $69 \%$ & $70 \%$ & $+6 \%$ \\
\hline$* 8$ & 23 & 32 & NIL & $64 \%$ & $64 \%$ & - & NIL \\
\hline *9 & 22 & 30 & 24 & $64 \%$ & $60 \%$ & 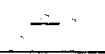 & $-4 \%$ \\
\hline 10 & 21 & 32 & 26 & $59 \%$ & $60 \%$ & $66 \%$ & $+7 \%$ \\
\hline$* 11$ & 23 & 32 & 14 & $60 \%$ & $64 \%$ & $\cdots-$ & $+4 \%$ \\
\hline 12 & 25 & 32 & 25 & $56 \%$ & $60 \%$ & $72 \%$ & $+16 \%$ \\
\hline$* 13$ & 22 & 24 & 25 & $61 \%$ & $61 \%$ & - & NIL \\
\hline 14 & 24. & 30 & 30 & $50 \%$ & $62 \%$ & $70 \%$ & $+20 \%$ \\
\hline 15 & 30 & 36 & 30 & $40 \%$ & $54 \%$ & $65 \%$ & $+25 \%$ \\
\hline 16 & 26 & 34 & 35 & $64 \%$ & $90 \%$ & - & $+26 \%$ \\
\hline 17 & 28 & 36 & 32 & $61 \%$ & $72 \%$ & - & $+11 \%$ \\
\hline 18 & 22 & 34 & 36 & $51 \%$ & $68 \%$ & - & $+17 \%$ \\
\hline
\end{tabular}

\section{Summary}

A report of 18 pregnant Gurkha women with anaemia of the microcytic hypochromic type, who were treated by using Imferon by drip of varying amounts, 14-36 millilitres, at stages of pregnancy, between 24-38 weeks.

The average rise in haemoglobin was 12.1 per cent.

\section{Conclusions}

Imferon by drip provides an effective means of raising the haemoglobin quickly.

It can be done in the unit, especially a Gurkha unit, where there is always a small family hospital.

It eliminates a number of attendances by the patients for intra-muscular or intravenous injections which are more painful.

There is no danger of leaving a permanent staining of the skin as can happen when Imferon is given intramuscularly. 
The two reactions in the series were not severe, one was easily controlled by intramuscular phenergan and in neither case was there adverse effects to either mother or child.

Having started the drip, the supervision of its progress can be delegated to a DI-AMAH or trained nurse, providing a briefing is given on side effects, etc.

\section{THE MCGRIGOR MANUSCRIPTS}

DURING 1963 I found it necessary to visit Great Britain to gather additional material for the biography of Sir Andrew Smith, M.D., K.C.B. While in Scotland, it occurred to me to investigate the history of the Aberdeen Medico-Chirurgical Society, which was founded by Sir James McGrigor in 1789, and which had elected Dr. Smith an honorary member in September, 1855. In doing so, the Society had presented him with an address, the original of which is in my possession.

I was therefore particularly anxious to examine the minute books of the Society, in order to see if Dr. Smith's reply had been preserved, and the honorary secretary, Dr. Clark, generously gave me access to them. In them I discovered a transcript of the important document for which I was seeking, though the original letter had not been preserved.

But while browsing through the excellent library of the Society, I came across a shelf full of manuscript volumes which had belonged to Sir James McGrigor, and which had been donated by him to the Society in 1847 . In one of these I found not only the letter which had accompanied the gift, but also a catalogue of the manuscripts in the collection. The letter, which was addressed to "The President of the Medical Society, Aberdeen ", was dated "London, 4th August, 1847" and had obviously been copied by a clerk, but signed by Sir James.

"Sir,

I send by the Ship (no name given) Volumes of Manuscripts being chiefly Cases of Disease which occurred in the Regimental Hospital of the 88th Regiment and of the Royal Regiment of Horse Guards when I was Surgeon of these Corps and subsequently when I was on the Medical Staff of the Army, and which I beg you to present in my name to the Medical Society of Aberdeen. In presenting these Volumes, I do so not on account of their value which I am very sensible is but small but as holding out to the Society an instance of the persevering Industry with which I prosecuted my profession from my first entrance into the Army and to which I mainly attribute my success in it. The Clinical Cases are generally in my own handwriting, but sometimes in that of my Assistants in the two Regiments in which I served as Surgeon, vizt. nearly 11 years in the 88th Regt. and about two years in the Royal Regiment of Horse Guards. My assistants were 